\title{
Meningeal Melanocytosis
}

National Cancer Institute

\section{Source}

National Cancer Institute. Meningeal Melanocytosis. NCI Thesaurus. Code C6890.

A diffuse or multifocal proliferation of uniform nevoid polyg onal cells in the

leptomeninges. Cells may spread into the Virchow-Robin spaces without frank invasion of the brain. Diffuse melanocytosis carries a poor prognosis even in the absence of histologic malignancy. (WHO) 